\title{
Biometric Analyses of Vibrissal Tactile Discrimination in the Rat
}

\author{
G. E. Carvell ${ }^{1}$ and D. J. Simons ${ }^{2}$ \\ Departments of ${ }^{P}$ Physical Therapy and ${ }^{2}$ Physiology, University of Pittsburgh, Pittsburgh, Pennsylvania 15261
}

\begin{abstract}
Blindfolded rats were trained to stretch across a gap to palpate rough or smooth surfaces with their mystacial vibrissae. Animals learned to discriminate reliably a smooth surface from a rough surface having shallow $(\sim 30 \mu \mathrm{m})$ grooves spaced at $90 \mu \mathrm{m}$ intervals. Field-by-field video analyses confirmed that rats used only their vibrissae to contact the discriminanda. The whiskers swept across the surfaces at $696 \%$ sec during forward movements and $1106^{\circ} / \mathrm{sec}$ for retracting movements. Mean amplitudes, which were $32^{\circ}$, were considerably smaller than the total arc through which whiskers can move. Rats maintained whisker contact with discriminanda for several hundreds of msec, during which time the animals repetitively swept their vibrissae across the surface at a dominant frequency of $8 \mathrm{~Hz}$. The range extended from 1 to $20 \mathrm{~Hz}$, and the frequencies utilized varied within and among subjects. Whiskers contacted the discriminanda along the hair shaft, not at the whisker tips. The hair shafts were bent continually but to varying degrees as an animal palpated the surface, and more than one of the large caudal whiskers were almost always in contact with it. Thus, whiskers are not used independently as rigid levers. Results indicate that the capacity of the rodent whisker system to distinguish a smooth surface from a rough one is comparable to that of primates using their fingertips and suggest common strategies for active touch in the mammalian somatomotor system.
\end{abstract}

The rodent somatic sensory system is characterized by a prominent representation of the mystacial vibrissae (Woolsey, 1967; Woolsey and Van der Loos, 1970; Welker, 1971). Each peripheral fiber innervating low-threshold whisker mechanoreceptors responds to 1 and only 1 vibrissa (Zucker and Welker, 1969), and, centrally, individual vibrissae are represented by aggregations of axon terminals and/or cell bodies (for a review, see Woolsey et al., 1981). Peripheral and central vibrissa units encode a variety of hair deflection parameters, including amplitude, velocity, duration, frequency, and angular direction (Zucker and Welker, 1969; Waite, 1973; Shipley, 1974; Simons, 1978; Ito, 1981). In some cases, amplitude thresholds are only a few tens of microns delivered $10-20 \mathrm{~mm}$ from the skin surface. These findings parallel early observations that acute removal of

\footnotetext{
Received Jan. 11, 1990; revised Mar. 12, 1990; accepted Mar. 29, 1990.

We thank Kathy Medlin for assistance with data collection and analysis, William Hughes for constructing the training apparatus, and Jason Carvell for artwork. This work was supported by the University of Pittsburgh Office of Research, NSF Grant BNS 8909620, and NIH Grant NS 19950.

Correspondence should be addressed to George E. Carvell, Ph.D., 101 Pennsylvania Hall, Department of Physical Therapy, School of Health Related Professions, University of Pittsburgh, Pittsburgh, PA 15261

Copyright C 1990 Society for Neuroscience $0270-6474 / 90 / 082638-11 \$ 03.00 / 0$
}

the vibrissae results in deficits in tactile discrimination, orientation, locomotion, and balance (Richardson, 1909; Vincent, 1912; for a review, see Gustafson and Felbain-Keramidas, 1977). Recently Hutson and Masterton (1986) used a conditionedsuppression technique to define rats' thresholds for detecting passively applied sinusoidal movements of a single vibrissa. Estimated velocity thresholds were as low as $0.3 \mathrm{~mm} / \mathrm{sec}$, and the lowest amplitude thresholds were $0.5^{\circ}$. Interestingly, thresholds were unaffected by lesions of the vibrissa region in the first somatic sensory cortex, but such lesions permanently impaired the ability of the animals to perform a gap-jumping task that involved active palpation of an object by the vibrissae.

Physiological studies have suggested that an important function of the rodent somatic sensory system is the integration of information arising from spatially and temporally patterned whisker deflections (Simons, 1978, 1985; Armstrong-James and Fox, 1987; Simons and Carvell, 1989). There is, however, a critical paucity of knowledge about how the animal actually uses its whiskers to obtain information about surface features in the tactile environment. To date, only 2 studies have described biometric aspects of whisking behavior. In a seminal study on rats, Welker (1964) described the ontogeny of whisking and the precise temporal coordination of vibrissae, nose, head, and respiratory movements. Wineski (1983) described the movements of whiskers in behaving hamsters and how, together, the individual vibrissal hairs form a planar sensory field around the animal's head. His results also suggested that animals might employ different whisking strategies during exploratory versus discriminative behaviors. Perhaps because of technical limitations involved with high-magnification viewing of whisker usage in free-ranging animals, these studies provided neither parametric information concerning the amplitudes and velocities of individual whisker movements, nor the nature of surface contact by the vibrissal hairs.

The purpose of the present investigation was 2 -fold. First, we wanted to establish that rats can, in fact, use their vibrissae to distinguish between objects differing only in surface texture. During the course of our study, Guic-Robles et al. (1989) reported that rats are able to discriminate sandpaper surfaces on the basis of vibrissal cues. The present results are consistent with these findings and, further, suggest that the capacity of the whisker system to distinguish a smooth surface from a textured one is comparable with that of primates using their fingertips. A second objective was to begin to describe in detail the biometrics of whisking behavior and the nature of mechanical contact between a whisker and an object during actively generated vibrissal movements. This required the development of a discrimination task wherein vibrissae and head movements were confined to a restricted physical location. Video analyses of animals performing this task confirmed its vibrissal nature and 


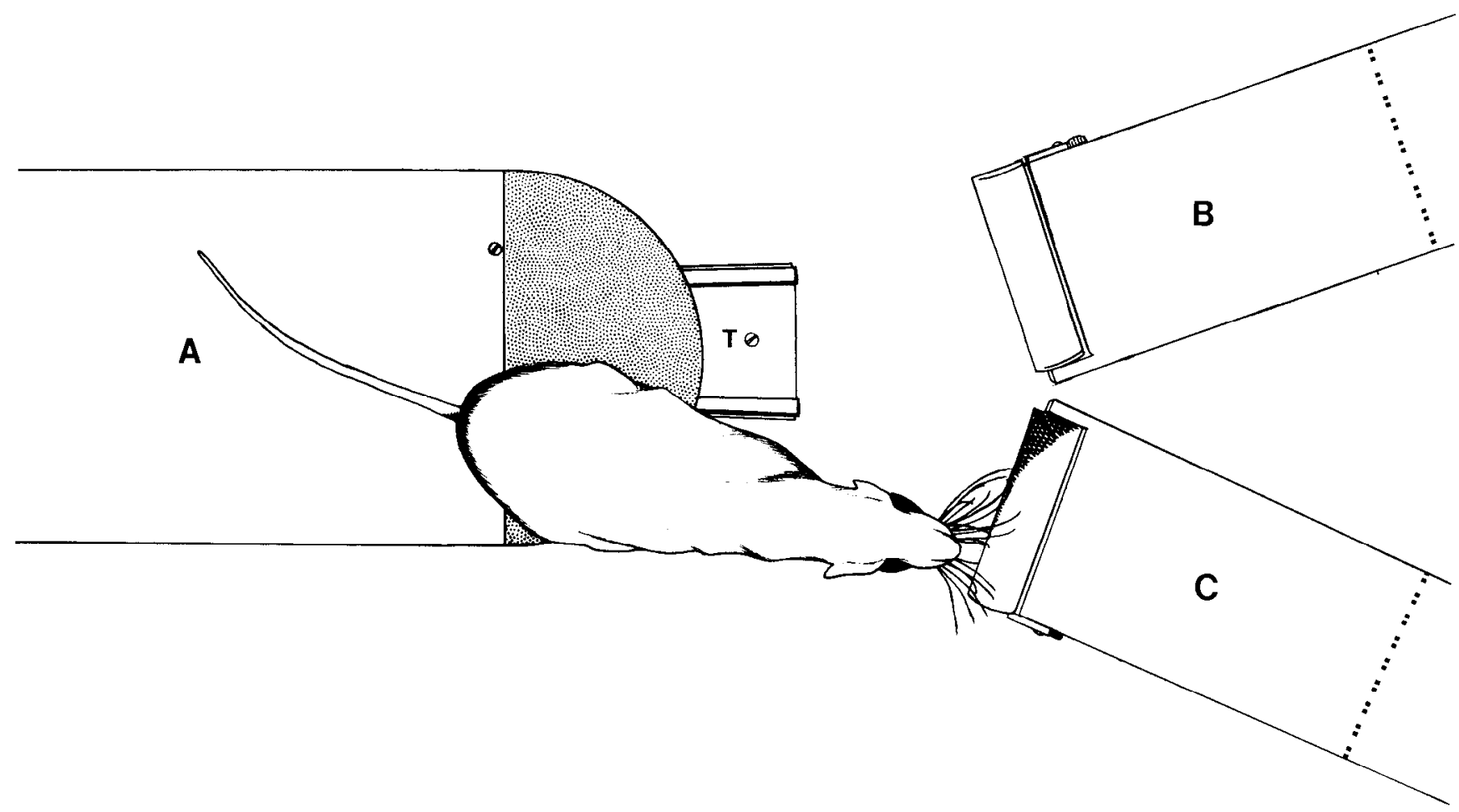

Figure 1. Testing apparatus and the behavioral task. Overhead view shows the relative positions of the 3 elevated platforms and a line drawing, based on a photograph, of a blindfolded rat palpating a textured discriminandum with its protracted vibrissae. The start platform $(A)$ has a nonskid surface (stippling), and the distance between it and the choice platforms $(B, C)$ can be adjusted by means of a calibrated track $(T)$. Discriminanda, which consist of smooth or milled plastic cylinders, are attached interchangeably to the front of the choice platforms. Food is placed behind perforated acrylic gates (dashed lines) on both choice platforms, but the gate is raised only after the animal jumps onto the platform having the correct discriminandum.

revealed the whiskers to be remarkably flexible and dynamic in their operation. We propose that the complement of mystacial vibrissae may be best regarded as a sensory array in which the individual whiskers function as components of a continuous receptive surface. The present findings have been reported previously in preliminary form (Carvell and Simons, 1988b).

\section{Materials and Methods}

Preparation. Six adult female albino rats (Sprague-Dawley, Hilltop Labs, Scottsdalc, PA) having initial wcights of 200-290 gm scrved as subjects in this study. Animals had access to food once each day for approximately $30 \mathrm{~min}$. Food consisted of a wet mash made from standard Purina rat chow mixed with water. The mash was also used as a reward during discrimination training. Animals had ad libitum access to water in their home cages. Throughout the study, all of the rats maintained their body weights within $10 \%$ of the normative values in age-matched animals.

At the outset, animals were anesthetized with Nembutal $(50 \mathrm{mg} / \mathrm{kg}$, i.p.) in order to custom fit each with removable blindfolds. These were constructed from stainless steel wire shaped into "glasses" that were fitted with opaque plastic lenses. The blindfolds were held in place by a small, stainless steel machine screw embedded in an acrylic skull cap. The acrylic cap was anchored to the bone using several \#00 self-tapping stainless stcel screws. When inserting the screws, care was taken to minimize their penetration through the inner table of the skull. A broadspectrum antibiotic ointment was liberally applied to the wound margins following the surgery. The skin adjacent to the cap was cleaned daily with diluted antiseptic. Two to $3 \mathrm{~d}$ after surgery, the rats became acclimated to the blindfolds by wearing them for a period of $1 \mathrm{hr} / \mathrm{d}$, during which time they were fed. Opthalmic ointment was applied to the inner surface of the lenses. During a 1 week acclimation period, the animals adapted well to wearing the blinders and to being handled by the experimenters. Animals subsequently wore the blindfolds only during the training session $(45-90 \mathrm{~min} / \mathrm{d})$.
Discrimination apparatus. The behavioral task required an animal to stretch across a gap in order to palpate a surface with its protracted vibrissae. The paradigm is a modification of one described originally by Richardson (1909) and used most recently by Hutson and Masterton (1986). The apparatus consisted of 3 black, anodized aluminum platforms that were elevated $25.5 \mathrm{~cm}$ above a base constructed of the same material (see Fig. 1). Animals were trained to jump from a start platform to 1 of 2 choice platforms for a food reward. The distance between the start platform and the 2 choice platforms could be adjusted by means of a calibrated track upon which the start platform glided. A food cup was placed at the end of each choice platform behind a perforated plastic gatc. The gatc was opencd by the cxperimenter only for those trials where the animal made a correct choice.

Discriminanda were made of high-density black plastic cylinders (Delrin, Dupont) that could be attached to the front of either choice platform (see Fig. 1). Rough discriminanda consisted of cylinders that were milled along their lengths with continuous spiral grooves of uniform depth and spacing. Discriminanda were examined using a dissecting microscope to measure their surface features. Coarsely textured surfaces had 2.4-mm-deep grooves spaced $3.2 \mathrm{~mm}$ apart ( 8 turns/inch) or 1.8-mm-deep grooves spaced $2.3 \mathrm{~mm}$ apart (11 turns/inch). During preliminary experiments, we serendipitously found that rats could detect differences between an unmilled (stock) cylinder and one that had been finely machined in preparation for another milling procedure. This latter surface had grooves spaced $\sim 90 \mu \mathrm{m}$ apart and $\sim 30 \mu \mathrm{m}$ deep. In order to cstimate a sensory threshold for this type of surface, another discriminandum was then made that had $\sim 15-\mu \mathrm{m}$-deep grooves spaced at $\sim 50-\mu \mathrm{m}$ intervals. Photomicrographs of the unmilled surface, which always served as the smooth discriminandum, and the $90-\mu \mathrm{m}$ surface are shown in Figure 2.

Training procedure. The animal was trained to distinguish between the smooth and rough surfaces and to indicate its choice by jumping from the start platform to one of the reward platforms. Prior to training, each rat was assigned randomly to 1 of 2 groups. Animals in one group were rewarded for choosing the platform having the rough surface, whereas animals in the other group were rewarded for choosing the 

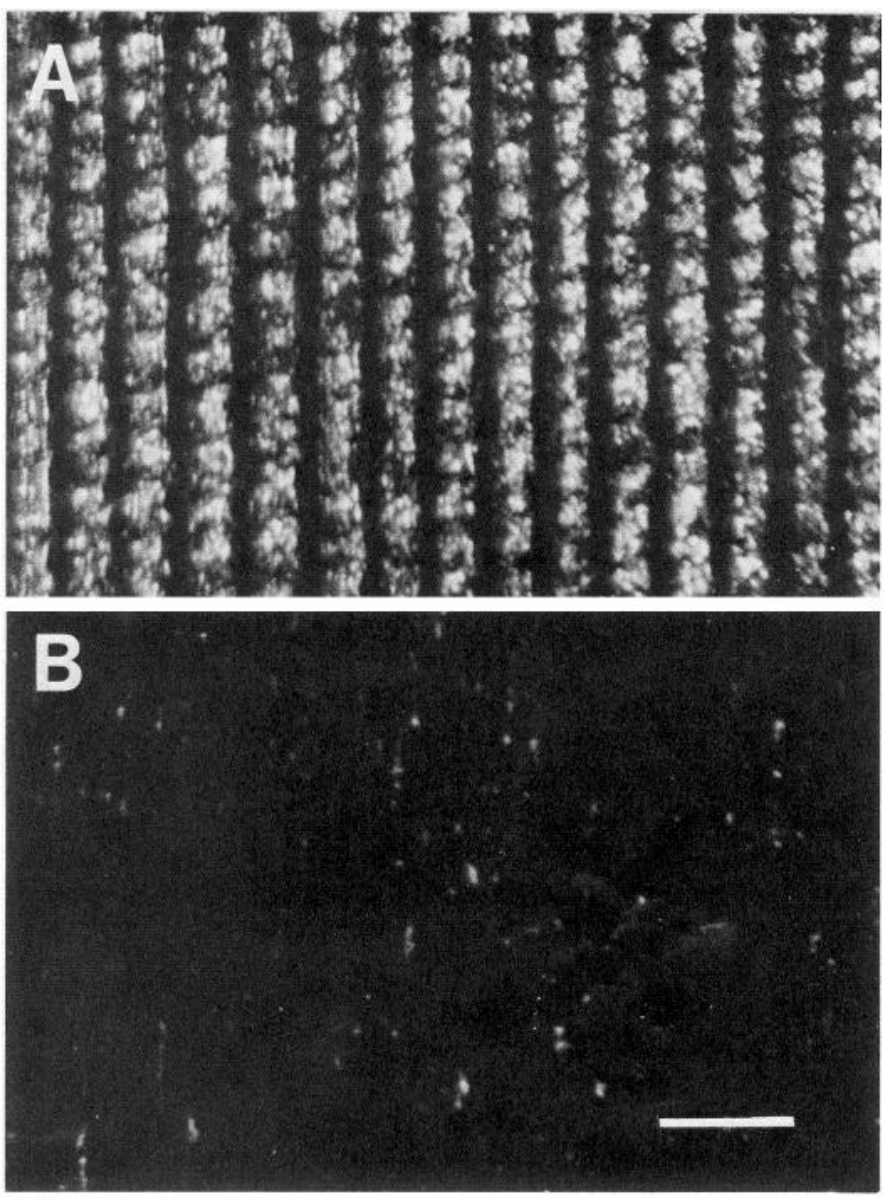

Figure 2. Light microscopic photographs of discriminanda. A, One of the rough surfaces, which has shallow ( $\sim 30 \mu \mathrm{m}$ deep) grooves spaced at $\sim 90 \mu \mathrm{m}$ intervals. $B$, The surface of the unmilled cylinder used as the smooth discriminandum. Scale bar: $200 \mu \mathrm{m}$.

smooth surface. Training began with the coarsest discriminandum $(8$ turns/inch). The blindfolded rat was placed upon the start platform, which was initially positioned close to the choice platforms. The animal was allowed a maximum of $90 \mathrm{sec}$ at the outset of training and $60 \mathrm{sec}$ later in training to move from the start platform onto 1 of the 2 choice platforms. If a correct choice was made within the allotted time, the rat was permitted $30 \mathrm{sec}$ of access to the food reward. An incorrect choice or failure to make a choice within the allotted time would terminate the trial without a food reward. The animals were not allowed to correct errors by returning to the start platform or by jumping to the other choice platform. As training progressed, the distance between the start and choice platforms was gradually increased so that the animal was eventually able to touch the discriminanda only with its whiskers (see Fig. 1).

Animals were tested 10 or 20 trials/d, and the order of testing for rats within the group was randomized daily. The location of the rough and smooth discriminanda on the right or left choice platforms was randomized for each trial, with the restriction that the reward stimulus not be located on the same choice platform for more than 2 consecutive trials. Additionally, the discriminanda and platforms were cleaned with alcohol between trials to remove potential odor trails.

An animal was considered to have successfully learned a discrimination task when it attained a score of $\geq 80 \%$ correct on $1 \mathrm{~d}$, with a score of $\geq 90 \%$ on each of the next $2 \mathrm{~d}$. When the animal attained criterion performance, a finer rough discriminandum was introduced.

Video analysis of whisking. Six trained animals were videotaped while performing the discrimination task. One d prior to the taping session, all large whiskers except those on the middle dorsal/ventral row (row $\mathrm{C}$ in the nomenclature of Woolsey and Van der Loos, 1970) were trimmed to a length of $\sim 1 \mathrm{~cm}$. The trimming was performed so that each of the remaining vibrissae could be more easily visualized and identified. It was necessary to expose the rats to the videotaping conditions for several $\mathrm{d}$ in order to acclimate them to the heat generated by the additional lights used for high-resolution video recording. Video images of whisking behavior were sampled at $60 \mathrm{~Hz}$ ( 60 fields/sec) using a video camera equipped with a macro lens and an electronic strobe-effect shutter that opened for $1 \mathrm{msec}$ (Panasonic D-5000). Images were recorded on standard $1 / 2$ " VHS cassettes. The camera was mounted above 1 of the discriminanda and focused so that individual whiskers could be visualized as they contacted its surface. Lens magnification was adjusted to provide the best compromise between high spatial resolution and adequate depth of field. A time/date generator with a stopwatch accurate to $0.01 \mathrm{sec}$ was placed in line with the video recorder to provide a permanent time record of the videotaped events. Recorded images were viewed on a high-resolution color video monitor (Panasonic CT 1930-V) using a VHS recorder that could display each field on a stop action basis (Panasonic AG 2500).

Data analysis. Videotaped trials were analyzed on a field-by-field basis. Trials selected for detailed analysis were those in which the animal made a correct decision and in which the row $\mathrm{C}$ whiskers on both sides of the face were clearly visible throughout the trial. For each field, the position of a whisker was traced onto transparencies overlaid on the video monitor. Data were obtained for each of 6 large, middle-row whiskers, the 3 most caudal ones on each side of the face. Using a transparent goniometer, the position of each whisker from one field to the next was measured at a distance of $1 \mathrm{~cm}$ from the base of the hair (see Fig. 3). Up to this point on the whisker, the hair shaft remained relatively straight, and angular displacements could be measured readily. Contacts with the discriminandum were coded on the transparency. Data were entered into a computer spreadsheet for manipulation and analysis. Using the changes in whisker position at each $16.67-\mathrm{msec}$ time interval, the velocity, amplitude, and temporal pattern of whisking movements were derived. Individual whisking sequences were analyzed by discrete Fourier transforms within the frequency range of $1-30 \mathrm{~Hz}$.

Whisking behavior in 9 selected videotaped trials from 3 rats were analyzed in detail. Two rats, $\mathrm{G}$ and $\mathrm{R}$, were discriminating between the $90-\mu \mathrm{m}$ rough surface and the smooth surface, and the third animal, rat $\mathrm{B}$, was discriminating between the 8-turn/inch surface and the smooth one. These animals had been trained by rewarding them for choosing the rough surface. For each rat, data for 2 trials were obtained as the animal whisked the rough surface, and one while whisking the smooth. Two thousand five hundred and ninety-two whisker movements (432 fields $\times 6$ vibrissae) were analyzed quantitatively.

\section{Results}

\section{General observations}

With 2 weeks of training, blindfolded rats learned the basic task of moving from the start platform to 1 of 2 choice platforms to receive a food reward. Typically, another $1-3$ weeks of training were required for an animal to attain criterion levels of performance in discriminating between a coarse surface ( 8 turn/inch) and the smooth one. During these early stages of training, the rats could use a number of tactile cues because the gap distance between the start and choice platforms was relatively short, permitting contact of the discriminanda by the forepaw, nose, and/or smaller perioral sinus hairs in addition to the whiskers. Over the next 8-12 weeks, the gap distance was adjusted for each rat so that the animal could reach the discriminanda only with its protracted mystacial vibrissae. Also, surfaces of finer texture were introduced as an animal attained criterion performance on a given task.

We found that blindfolded rats could use their vibrissae to reliably distinguish ( $>85 \%$ correct choices) a smooth surface from a rough surface consisting of shallow ( $\sim 30 \mu \mathrm{m}$ depth) grooves spaced only $90 \mu \mathrm{m}$ apart (see Fig. 2). One animal, which consistently performed this task correctly, was also tested on the $50-\mu \mathrm{m}$ surface. This rat was unable to distinguish it correctly from the smooth surface in spite of 2 months of testing during which the $50-\mu \mathrm{m}$ surface training sessions were periodically interspersed with training sessions using the $90-\mu \mathrm{m}$ surface. 
The finding that a well-trained animal can distinguish the 90$\mu \mathrm{m}$ surface but not the $50-\mu \mathrm{m}$ one indicates that rats in this study were using texture rather than unintended, nontactile (e.g., olfactory or visual) cues. As a direct control for the possible use of visual cues, 1 animal was trained on the coarsest surface in the light and without wearing a blindfold. During a $43 \mathrm{~d}$ training period, during which 430 trials were run, this animal never reached criterion performance. In fact, this rat often leapt to one of the choice platforms with little or no whisking of either discriminandum prior to the jump. Therefore, it appears that the discrimination task requires blindfolded rats to rely solely on vibrissal cues, a conclusion also supported by the video analyses (see below).

\section{Behavioral strategies}

The blindfolded rats readily located the discriminanda by sweeping their vibrissae through the air and moving their heads. Typically, animals then positioned themselves to the right or left of center at the front edge of the start platform, whereupon they stretched across the gap to brush their whiskers repetitively across the discriminandum on that side. Following this, a rat would: (1) jump to that platform, (2) retract its head and slightly reposition its body to palpate the same surface again, or (3) move to a new position on the start platform so that it could whisk the other discriminandum. An animal would often repeat 1 of the 2 latter sequences several times before jumping to a choice platform. This was particularly true for well-trained animals that were working on the finer-textured surfaces. Examination of 81 videotaped trials of 3 such animals revealed that, in $41 \%$ of the trials, the rat approached and whisked only 1 discriminandum before jumping to that platform. For the remaining trials, animals would explore separately each of the discriminanda 1-5 times before jumping to one of the choice platforms. Only rarely did a well-trained animal stretch across the gap to palpate both discriminanda simultaneously. Although the difference was not statistically different ( $\chi^{2}$ test, $p>0.05$ ), it is nonetheless interesting that, for well-trained rats, the single "whisk-and-go" strategy was associated with a correct choice $73 \%$ of the time, whereas repeated exploration of one or both discriminanda was followed by a correct choice $86 \%$ of the time. In addition, animals always jumped accurately onto the choice platform, indicating that they were able to use their vibrissae to gauge the distance to and the width of the choice platform. The abilities of the rats are remarkable considering that during videotaping they were performing under the additional heat of the studio lights and all but 1 row of their whiskers on each side of the face had been trimmed (see Materials and Methods).

Regardless of the strategy an animal adopted in projecting its head towards the discriminanda, blindfolded rats always actively whisked the surfaces before jumping. The large, caudal vibrissae were rhythmically protracted and retracted while the animal approached the discriminanda, during which time there were no objects within the vibrissal field, as well as while the animal palpated the surface by actual whisker contact. A particularly interesting observation, illustrated in Figure 3, is that the small, rostralmost sinus hairs always remained in a relatively motionless, protracted state while the rat first approached the discriminandum; once the surface was contacted, these small whiskers remained protracted, never losing contact with the surface, until the animal either jumped to or retreated from the platform. Concurrently, the large, caudal whiskers actively palpated the discriminandum.

\section{Whisking frequency}

Rats searched for the discriminanda by repetitively protracting and retracting their vibrissae at approximately $8 \mathrm{~Hz}$. Upon contacting a discriminandum, the rat continued to rhythmically sweep its vibrissae across the surface. For the 9 videotaped trials that were analyzed in detail, surface contact was maintained by at least 1 of the large vibrissae for an average of $684 \mathrm{msec}$ (range, 333-1100 msec). More than 1 adjacent whisker contacted the discriminandum in $54 \%$ of the fields showing surface contact behavior. In $36 \%$ of such fields, 2 adjacent whiskers simultaneously touched the discriminandum; in $18 \%$, all 3 whiskers did so. Loss of contact occurred most often for the caudalmost vibrissa at its point of maximal retraction. Inasmuch as these analyses were applicd to only a single row of whiskers (sce Materials and Methods), it is highly probable that surface contact is normally accomplished by more than 1 large whisker at a time, that is, by the more rostrally located, large vibrissae in several whisker rows (see Fig. 1).

Figure $4, A$ and $B$, illustrates the whisker movements as rat $\mathrm{G}$ palpated the $90 \mu \mathrm{m}$ rough surface, the reward stimulus for this animal. At the beginning of the sequence (time 0 ), the animal was approaching the discriminandum, which subsequently was contacted by all but 1 of the vibrissae at the 17th frame. Contact with the surface was maintained for the remaining 49 fields, after which the animal jumped to the rough platform to obtain a food reward. The overall movement is cyclic, recurring every 7 or 8 fields. Fourier power spectra for each whisker (Fig. 4, C, $D$ ) demonstrate a dominant frequency of $8 \mathrm{~Hz}$ and a less prominent but consistent peak at $12 \mathrm{~Hz}$. In addition, as seen in Figure $4, A$ and $B$, whiskers on the left side of the face move synchronously with each other and with vibrissae on the right side. This pattern was typical for the vast majority of the analyzed sequences. Incongruous movements occurred more frequently between whiskers on the opposite sides of the face than among whiskers on the same side. Of the 2,592 movements analyzed, the large caudal whiskers on the right and left sides moved in opposite directions $11 \%$ of the time, whereas dissimilarities in the direction of movement among whiskers on the same side were observed only $3 \%$ of the time.

\section{Protractions and retractions}

As evident in Figure 4, protractions are of slower velocity than retractions and occupy a correspondingly longer portion of the whisking cycle (see also below). In addition, protractions were often interrupted by brief reversals in the direction of whisker movement, resulting in a high-velocity perturbation of a hair's overall motion. These perturbations appear to reflect actively generated movements because they are large with respect to the surface features of the discriminandum, and because they occur synchronously among adjacent whiskers. Figure 4 illustrates further that, upon surface contact, whiskers on the right side flaired out so that the distances between them, relative to their initial position, increased, whereas whiskers on the left side converged. Concurrently, the animal was moving its head to the left, a motion that would appear to have caused a passive compression of the vibrissal field on the leading (left) side and an expansion on the trailing (right) side. Thus, the nature of whisker contact with a surface depends on actively generated movements of both the vibrissae and the head.

Field-by-field analyses of whisker movement revealed that protractions occurred $57 \%$ of the time, retractions $37 \%$. In $6 \%$ 
E

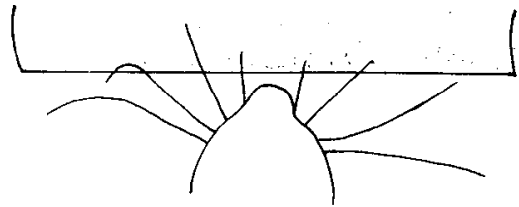

D

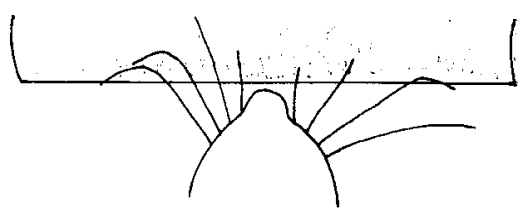

Figure 3. Whisker usage by discriminating rats. Panels $A-E$ are line-drawing reconstructions of sequential video fields at $16.67 \mathrm{msec}$ intervals, showing part of a single whisking cycle. On each side of the face, 4 whiskers are drawn, 1 of the small, rostral sinus hairs and the 3 caudalmost vibrissae in the middle dorsal/ventral row. Scale bar: $1 \mathrm{~cm}$, $\mathrm{r}$, rostral; $\mathrm{m}$, middle; $\mathrm{c}$, caudal. The sequence shows 3 protraction fields $(A-$ $C)$ and 2 retracting fields $(D, E)$. Note the bending and mobility of the large vibrissae compared to the small, rostralmost hairs. $F$, The method used to measure whisker displacement from one field to the next. Dotted lines show positions of whiskers from $A$, solid lines show positions of same whiskers from $B$, and $\theta$ is the angle of movement measured $1 \mathrm{~cm}$ from the skin surface. $G$, A composite of frames $A-E$ showing the total excursion of each whisker.

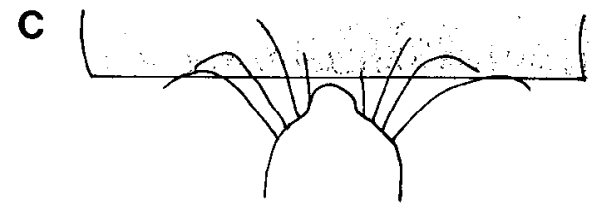

$\mathbf{B}$

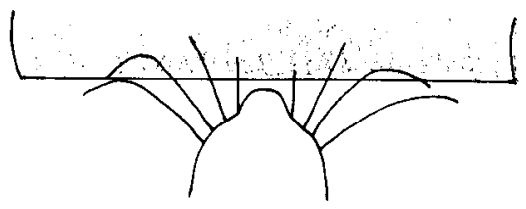

A

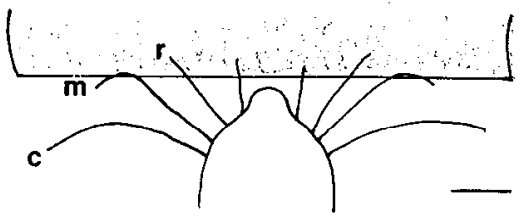

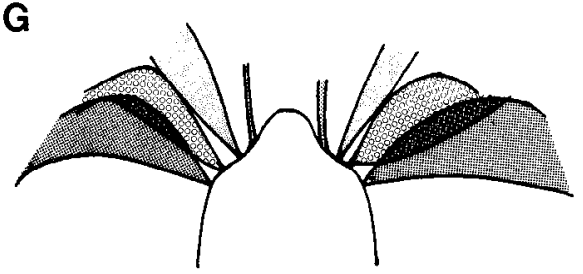

F

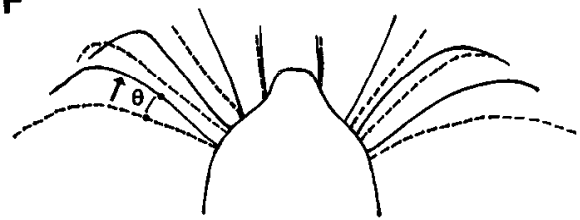

of the cases, a whisker did not move detectably. From one sampled field to the next, a forward-moving whisker would move through an average arc of $10.91^{\circ} \pm 7.22^{\circ}$, and a caudally moving whisker would move through an arc of $16.28^{\circ} \pm 12.15^{\circ}$. This difference would result in a net retraction of whisker position over several cycles of retractions and protractions if each accounted for $50 \%$ of the frames. However, when the fields where whisker movement was not detected are disregarded, it was found that protractions account for $60 \%$ and retractions $40 \%$ of the complete cycle. The net average protraction $\left(10.91^{\circ}\right.$ $\left.\times 0.60=6.55^{\circ}\right)$ and retraction $\left(16.18^{\circ} \times 0.40=6.51^{\circ}\right)$ are thus virtually equivalent. In terms of average velocity, protractions are slower than retractions $(654.6 \% \mathrm{sec}$ vs $976.8 \% \mathrm{sec})$.

\section{Whisking cycles}

Further analyses were performed in order to derive the amplitudes and angular velocities of whisker motion during individual protracting and retracting sweeps. An individual "sweep" was defined as consisting of 2 or more consecutive frames in which the whisker moved in the same direction. The beginning and ending points were defined as the hair's location in the second of 3 frames within which the direction of movement changed and the movement between the second and third frames was $\geq 5^{\circ}$; if the movement was $<5^{\circ}$, the second position was still considered a transition point if the hair's movement between the third and fourth frames was in the same direction as between the second and third. Partial sweeps at the beginning and end of each trial were discarded. Results are shown in Figure 5, which shows amplitude and velocity data for 421 protracting sweeps and 418 retracting sweeps. As described above, protractions were slower than retractions $(696 \pm 330 \%$ sec vs 1106 $\left.\pm 565^{\circ} / \mathrm{sec}\right)$. The mean amplitudes of protractions and retractions are virtually identical $\left(31.6^{\circ} \pm 14.7^{\circ}\right.$ vs $\left.32.1^{\circ} \pm 15.3^{\circ}\right)$, and this equivalence is also consistent with the field-by-field analyses. Interestingly, other analyses showed that the average maximal excursion of whisker motion is $56.2^{\circ} \pm 15.4^{\circ}$. Therefore, the amplitude of an individual sweep is considerably less than the arc through which a whisker can move.

From the data shown in Figure 5, it is possible to estimate the average speed at which whiskers sweep across a discriminandum's surface. Of the 3 whiskers measured, the rostral vibrissa typically contacted the discriminandum at a distance of $-10-15 \mathrm{~mm}$ from the skin surface, and the caudal vibrissa contacted it at a distance of $\sim 15-20 \mathrm{~mm}$. Thus, for an "average" whisker contacting a discriminandum $15 \mathrm{~mm}$ from its emergence from the sinus hair follicle, the distance swept across the surface is approximately $9.3 \mathrm{~mm}$. Estimated velocities are therefore $182 \mathrm{~mm} / \mathrm{sec}$ for protractions and $290 \mathrm{~mm} / \mathrm{sec}$ for retractions. Velocities decrease for contacts closer to the base of the hair, and vice versa (e.g., at $10 \mathrm{~mm}$ along the hair shaf the average protraction velocity is $122 \mathrm{~mm} / \mathrm{sec}$ ).

\section{Effects of surface contact}

Field-by-field analyses indicated that whisker contact with a discriminandum reduced the size of whisker movements (see Fig. 6). Protractions were smaller when the whisker touched the 


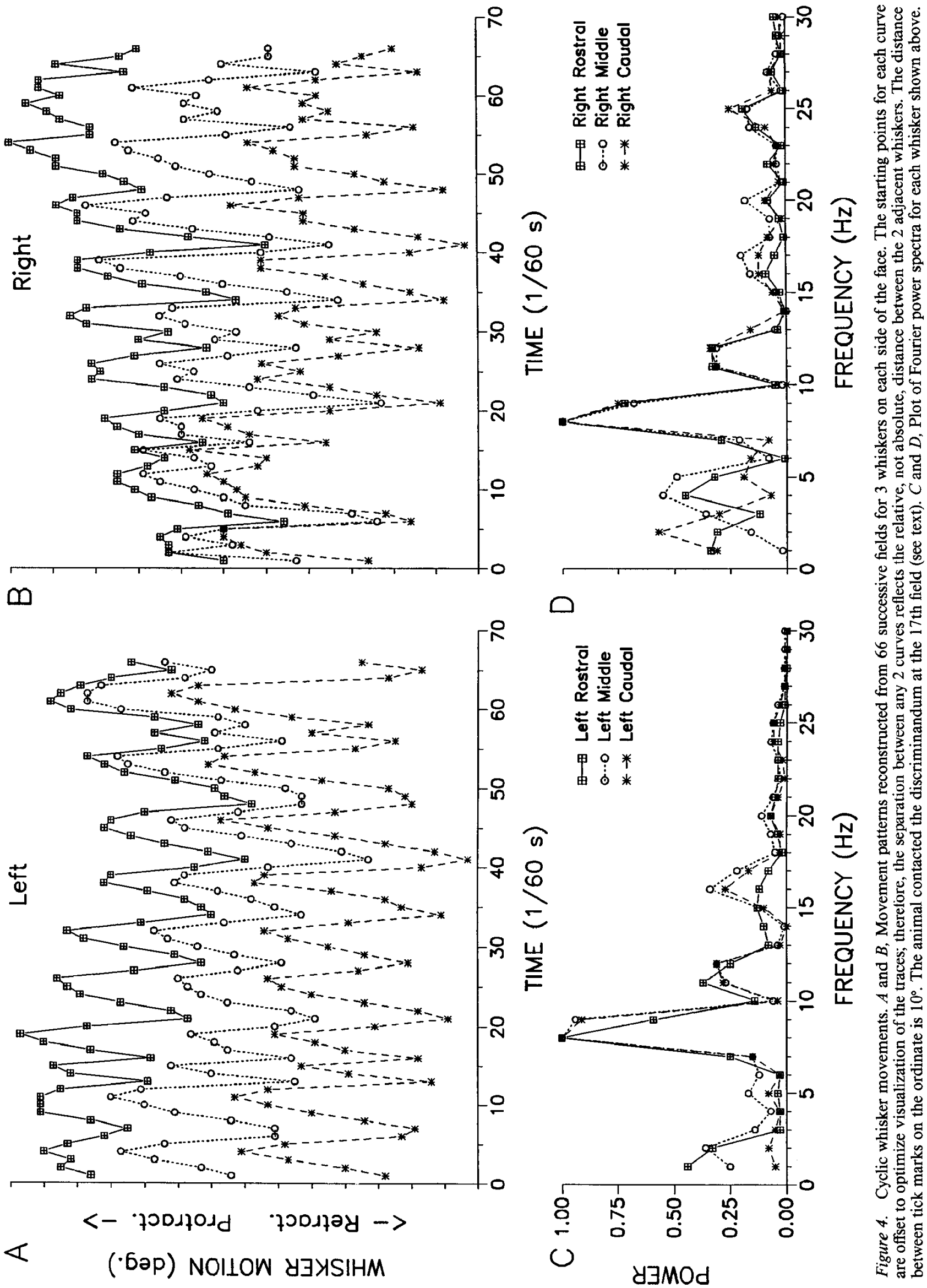



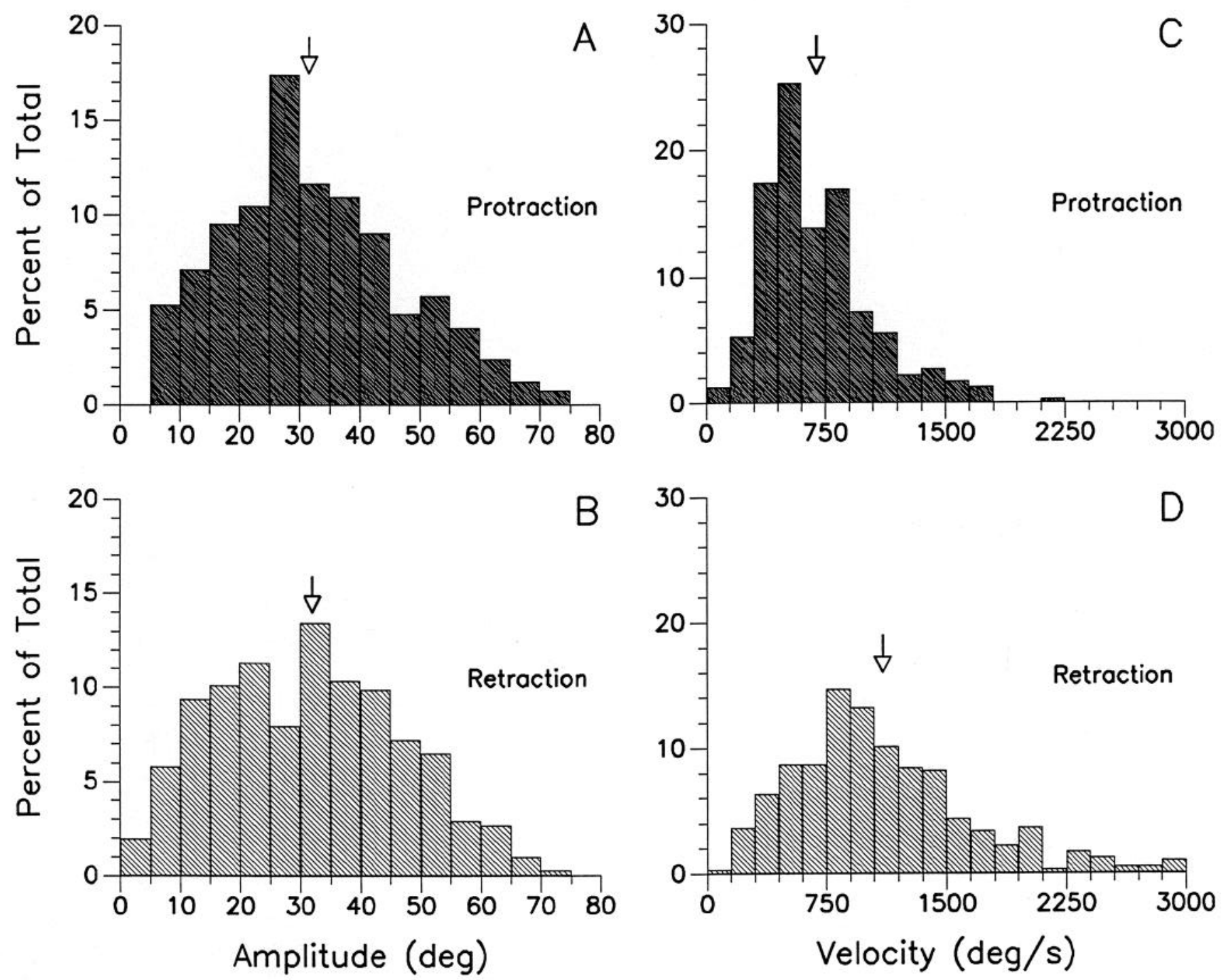

Figure 5. Amplitudes and angular velocities of whisker motion during individual protracting and retracting sweeps. Arrowheads denote means. Data are based on 421 protractions and 418 retractions; for "sweep" definition, see text.

discriminandum than when it did not $\left(9.63^{\circ} \pm 6.29^{\circ}\right.$ vs $12.46^{\circ}$ $\left.\pm 7.93^{\circ}\right)$. These differences are more pronounced in the case of retractions $\left(11.70^{\circ} \pm 8.21^{\circ}\right.$ vs $\left.19.18^{\circ} \pm 13.30^{\circ}\right)$. For both types of movements reductions were similar for the rough and smooth surfaces. Surface contact also affects whisker velocity. Table 1 compares the estimated speeds at which a whisker moves through the air and at which it moves across a discriminandum. As above, it is assumed that the whisker contacts the discriminandum $15 \mathrm{~mm}$ from the skin surface. Note that retractions through the air are twice as fast as protractions against the discriminandum.

Surface contact not only affected the amplitude and velocity of whisker movements, it could also dramatically alter the contour of the hair. As illustrated in Figure 3, some whiskers would bend upon contact with the surface, and some would not. In the former case, the whiskers were bent caudally and perpendicular to the alignment of the grooves on the cylindrical discriminandum. The whisker would typically remain deformed as it swept across the surface. In some cases, the bending of the hair shaft was so pronounced that the tip of the whisker no longer touched the surface. Thus, the bowed aspect of the hair shaft, not its tip, was the interface between the textured surface and the animal. In fact, we never observed even a relatively straight whisker contact the surface only at its tip; like bent whiskers, such a whisker contacted the surface on the hair shaft. The spatial resolution of the video data was not sufficient for detailed analyses of whisker perturbations as the animal palpated objects of different textures. Nevertheless, the data clearly demonstrate that whiskers do not act as simple rigid levers.

\section{Variations in temporal patterns of whisking}

Figure $7 A$ shows the average Fourier power spectra derived from 3 animals as they successfully performed 3 discrimination tasks. This profile illustrates the aforementioned dominant whisking frequency of $8 \mathrm{~Hz}$, with other prominent components in the range of $2-20 \mathrm{~Hz}$. On average, there are no pronounced differences in the whisking frequencies used by subjects palpating the smooth versus rough surfaces. However, as shown in Figure 7, $B-D$, there are within-subject and across-subject variations. For each animal, there is at least 1 trial in which a predominant $7-$ 


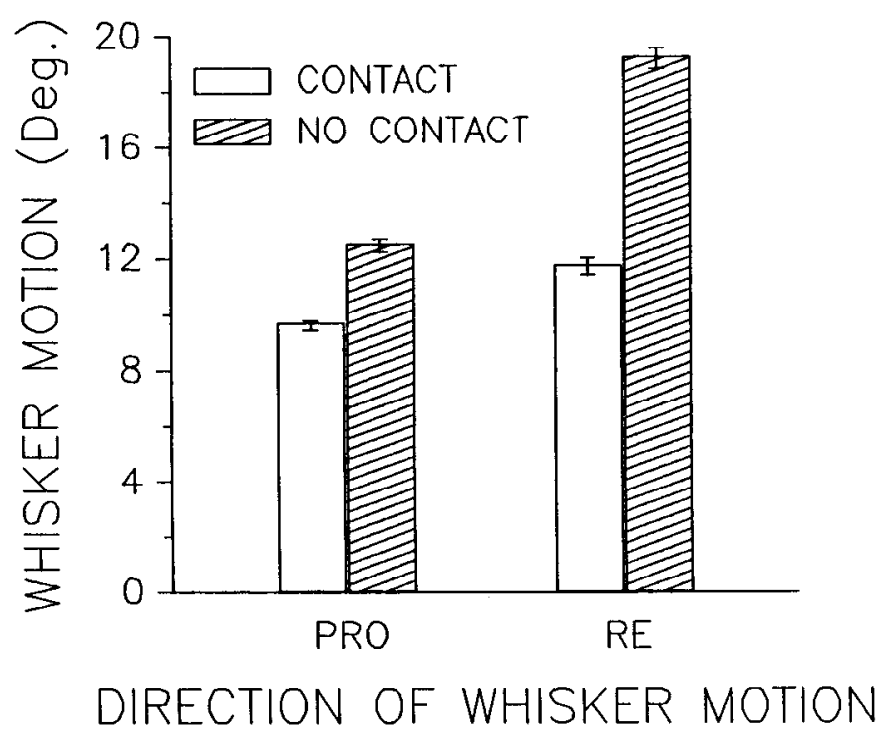

Figure 6. Effects of surface contact on the amplitude of whisker movements. For each of 6 whiskers, 432 fields were examined to determine the angular displacement of the whisker hair during successive fields when it was contacting a discriminandum and when it was sweeping the air only (no contact). Error bars denote means and SEM; PRO, protractions; RE, retractions.

9-Hz movement pattern was observed. The subject of panel $B$ displayed this characteristic frequency on only 1 trial, during which the rat was palpating the smooth surface. In the 2 other trials (rough surface), the animal moved its whiskers at a considerably lower frequency. The rat in panel $C$ differed from the other 2 animals in that it consistently displayed high-frequency components during whisking. The task for this subject was to discriminate a coarse surface from the smooth one, whe eas the animals of panels $B$ and $D$ were distinguishing between a finer surface and the smooth discriminandum. Interestingly, despite the differences in the temporal pattern of whisking in these trials, in each case the rat made the correct choice. In this regard, the frequency of whisking may be a less important parameter than the actual velocity at which a whisker moves across the surface; that is, rats might adjust the amplitude of individual sweeps to achieve a relatively fixed velocity of whisker-surface contact. However, examination of the data revealed that, like whisking frequency, sweep amplitudes and velocities varied over a fairly broad range. Analyses of variance showed that neither amplitude nor velocity differed significantly for trials characterized by low-frequency whisking and those characterized by highfrequency movements. Whether whisking frequencies are consistently related to changes in surface texture, level of training, or task difficulty cannot be determined on the basis of the present sample. What is clear, however, is that whisking behavior is not strictly stereotyped.

\section{Discussion}

The present findings are consistent with those of Guic-Robles et al. (1989) in demonstrating that rats can use their mystacial vibrissae to obtain useful information about the surface texture of objects in the environment. The discrimination capability of these animals is quite remarkable inasmuch as blindfolded raîs are able to perform reliably rough-smooth discriminations that we ourselves found challenging using our fingertips. Although
Table 1. Effects of surface contact on velocity of whisker motion

\begin{tabular}{lll} 
& \multicolumn{2}{l}{ Whisker-Surface relation } \\
\cline { 2 - 3 } Movement & Contact & No contact \\
\hline Protraction & $578 \% \mathrm{sec}$ & $748 \% \mathrm{sec}$ \\
& $150 \mathrm{~mm} / \mathrm{sec}^{a}$ & $196 \mathrm{~mm} / \mathrm{sec}^{a}$ \\
Retraction & $702 \% / \mathrm{sec}$ & $1151 \% / \mathrm{sec}$ \\
& $184 \mathrm{~mm} / \mathrm{sec}^{a}$ & $302 \mathrm{~mm} / \mathrm{sec}^{a}$ \\
\hline
\end{tabular}

${ }^{a}$ At $15 \mathrm{~mm}$ along the hair shaft.

we have not yel established precise thresholds, our findings indicate that rats can detect reliably shallow grooves spaced at no more than $90 \mu \mathrm{m}$. For comparison, trained human subjects palpating surfaces with raised dots or gratings are able to detect differences in the spacing of these features of 40-80 $\mu \mathrm{m}$ (Lamb, 1983; Morley et al., 1983).

We are confident that the task used in the present study is vibrissally based. Video analyses clearly indicated that mechanical contact between a discriminandum and the rat prior to its jump was limitcd to the vibrissac. Also, the animals' ability to perform the discrimination task successfully depended specifically on the spatial frequency of the rough surface. It is conceivable that the rats detected the sound of whiskers vibrating as they swept across the surface grating. Although we cannot presently dismiss this possibility with certainty, the obvious flexibility of the hair shafts and the elasticity of the mystacial pad in which the hairs are embedded suggest that whisker vibrations are not likely to generate significant airborne or boneconductive microphonics.

In order to palpate a discriminandum, rats projected their whiskers forward at an acute angle and superimposed upon this protracted state a rhythmic to-and-fro movement of the vibrissal hairs. Consistent with the findings of Welker (1964) in the rat and Wineski (1983) in the hamster, we observed that the large, caudal whiskers typically move together. Wineski described the whisker hairs of the hamster as being of different lengths and curvatures such that, in a fully protracted state, the array of mystacial vibrissae forms a plane of tactile sensors in front of the animal. Anatomical and behavioral evidence suggest that rostral and caudal whiskers within this planar array serve different functions. The large, caudal whiskers are associated with 2 types of striated musculature, one that moves the whole mystacial pad, and one that directly moves each sinus hair follicle; the rostralmost vibrissae lack the latter muscle system (Dörfl, 1982). Consistent with these findings, Wineski (1983) reported that the small, rostral vibrissae move less than the large, caudal ones. In the present study, the differential mobilization of the small, rostralmost vibrissae and the 3 caudalmost whiskers was a prominent aspect of the strategy adopted by the animals: the former remained in a relatively motionless, protracted position while the latter swept repetitively across the discriminandum.

It appears to us that the animals used the rostralmost whiskers to gauge the location of the surface while the caudal whiskers palpated it. The differential usage of these 2 groups of whiskers parallels differences in the sensory innervation of the follicles. Thus, in the case of the caudal whiskers, trigeminal afferents innervate the superficial aspect of the follicles (i.e., the conus), whereas such innervation is lacking in the case of the rostral vibrissae. Comparative studies have demonstrated a positive 

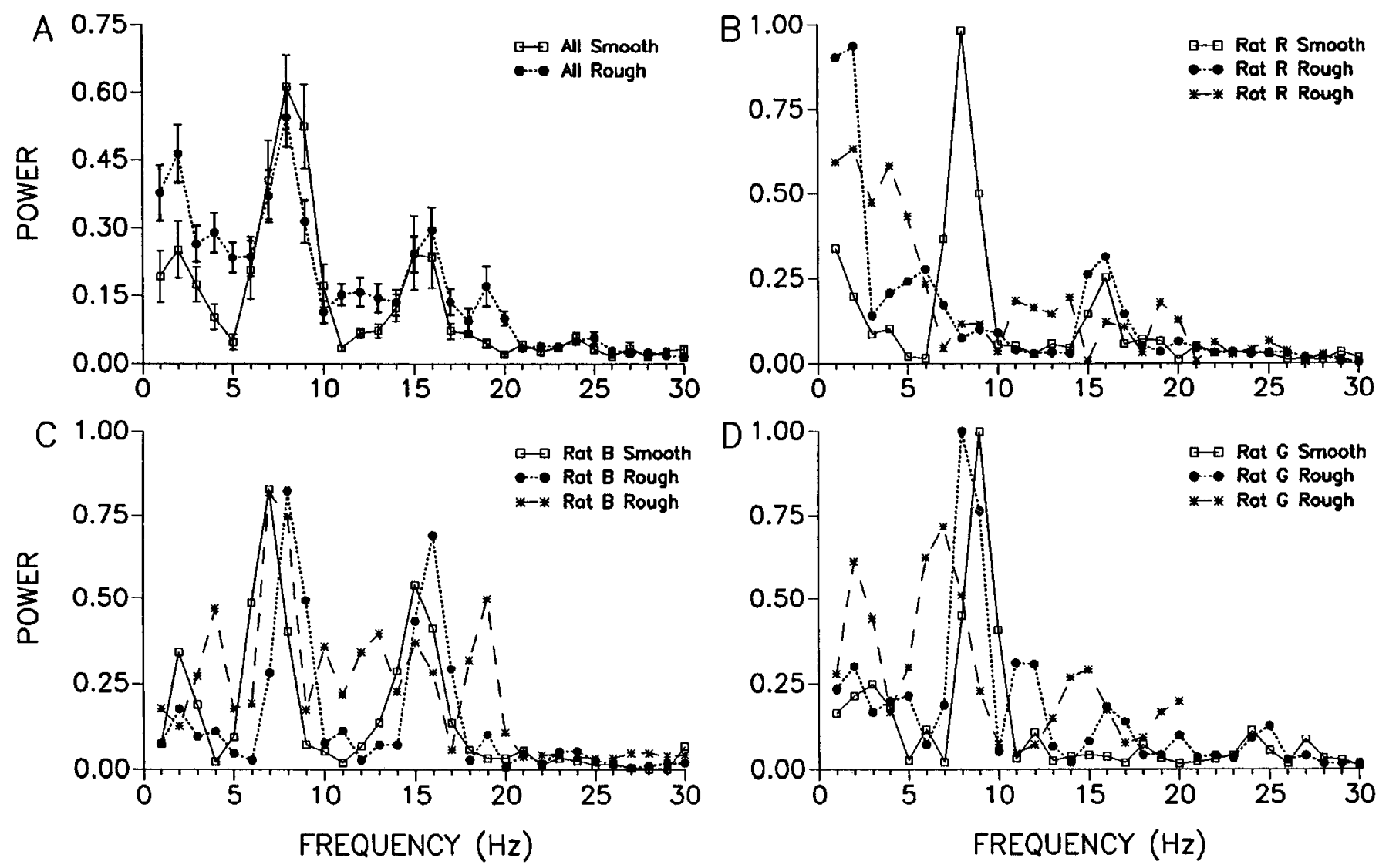

Figure 7. Fourier power spectra of whisking behavior. A, Averaged data for 3 animals during 3 trials each. For 2 trials, animals were palpating the rough surface; for the other trial, the smooth one. Error bars: \pm 1.0 SD. $B-D$, Data for each individual trial that reveal variations in the temporal pattern of whisking within and among animals (see text).

correlation between the extent of conus innervation and active whisking in different species, suggesting that the conus nerves provide sensory feedback independent of the signal transduced by actual mechanical contact between the hair and an object (Rice et al., 1986). Such kinesthetic information may be important in controlling the relatively fine movements of the caudal whiskers during discriminative touch. This hypothesis is consistent with our finding that sweep amplitude during active touch represents only a fraction of the range of motion of which a whisker is capable.

Several lines of evidence suggest that the whiskers do not serve as absolute referents in a fixed spatial coordinate system. In normal adult rats, vibrissae continually grow and are replaced (Ibrahim and Wright, 1975). During the growth cycle, the whisker hair undergoes changes in length and caliber; at some growth stages, 2 whiskers emerge from a single follicle. These changes will effect the geometry of the whisker field, as well as the stiffness of the hairs. The latter is presumably a critical factor in the translation of mechanical signals into perturbations of the mechanoreceptors within the sinus hair follicle. During active touch, whiskers move synchronously, and several of them touch the surface together. Such contacts may last several hundred msec, causing 1 or more whiskers to remain bent to varying degrees. Also, head and body movements continuously alter the position of the distal end of each hair shaft relative to other whiskers in the array. It may be useful, therefore, to regard the whisker field in its function as a continuous receptive sheet, more akin to glabrous or hairy skin than the punctate anatomical character- istics of the vibrissa system might offhandedly suggest. Consistent with this idea are physiological studies demonstrating substantive similarities between the receptive field properties of vibrissa neurons in the rodent somatic sensory cortex and those of cutaneous units in the somatic sensory cortex of other species. These similarities include constraints on neuronal responsiveness to temporally patterned stimuli (Mountcastle et al., 1969 . Simons, 1978, 1985; Ferrington and Rowe, 1980; Gardner and Costanzo, 1980b) and the spatial organization of afferent inhibition within cortical receptive fields (Mountcastle and Powell, 1959; Hellweg et al., 1977; Gardner and Costanzo, 1980a; Simons, 1985; Carvell and Simons, 1988a; Simons and Carvell, 1989). Moreover, the cortical forelimb representation in cats and monkeys contains a mosaic of discrete columnar units, called segregates (Favorov et al., 1987; Favorov and Whitsel, 1988), that are functionally reminiscent of whisker harrel columns in the rodent (Simons, 1978; Chapin, 1986; ArmstrongJames and Fox, 1987).

A striking feature of vibrissal tactile behavior is its rhythmicity. We found that, during discriminative behavior, rats whisk their vibrissae at a dominant frequency of $8 \mathrm{~Hz}$, with other prominent frequencies at approximately 2 and $16 \mathrm{~Hz}$. Welker (1964) observed that exploring rats also sweep their whiskers at 6-9 cycles/sec. Mice display a dominant whisking frequency of $8-10 \mathrm{~Hz}$ with an upper value of approximately $15 \mathrm{~Hz}$ (Woolsey et al., 1981), and hamsters whisk at frequencies of $9-23 \mathrm{~Hz}$ with a mean of 16 cycles/sec (Wineski, 1983). A variety of other rodent species display whisking behaviors, though the extent of 
variation in whisking patterns has not been defined (see Wineski, 1983).

Rats can extract relevant texture information from whiskers that move over defined but broad ranges of frequencies, amplitudes, and velocities. A 30 -fold range of frequencies characterizes optimal detection of vibratory stimuli delivercd passively to a single vibrissa (Hutson and Masterton, 1986). For human and nonhuman primates, the range of velocities associated with optimal texture or motion-direction discrimination varies over a 10 -fold range $(\sim 3-30 \mathrm{~cm} / \mathrm{sec})$, as does the velocity tuning of direction-sensitive neurons in the monkey somatic sensory cortex (for recent reviews, see Essick and Whitsel, 1985, 1988). Interestingly, rats sweep their vibrissae across a textured surface at average velocities of $180 \mathrm{~mm} / \mathrm{sec}$ during protraction and $290 \mathrm{~mm} / \mathrm{sec}$ during retraction. For the former case, values are well within the range of velocities for cutaneous discriminations noted above.

For the primate hand, tactile discriminations are enhanced by motion between an object and the fingertips (Darian-Smith, 1984). In this regard, the to-and-fro movements of the whiskers may constitute a strategy whereby relative motion between the vibrissal hairs and an object is maintained for extended periods. Because movement of the whiskers is physically limited by the nature of the mystacial pad, the major function of vibrissal retraction may be the resetting of the position of the whiskers, in a fashion perhaps analogous to optokinetic eye movements. A resetting function for retractile movements is consistent with Welker's findings (1964) and ours that retractions occur more quickly than protractions. Striated muscle fibers mediating protraction form a sling around the rostral aspect of each hair follicle; contraction of these muscles via branches of the facial nerve pulls the base of the follicle caudally, moving the distal aspects of the whisker hair forwards (Dörfl, 1982; Wineski, 1985). By contrast, retraction of the vibrissae may depend primarily upon passive, elastic properties of deep tissue; actively generated retractions might occur only with extreme movements of the caudal vibrissae via accessory pad musculature (Dörfl, 1982; Wineski, 1985). Our finding, that protraction amplitudes are less affected by surface contact than are retraction amplitudes, is consistent with the idea that the former are subject to a greater degree of muscular control than the latter. Such control may depend, in part, on kinesthetic information provided by the conus innervation of the caudal vibrissae (see above).

We are struck not only by the exquisite tactile sensitivity of the rat vibrissal system, but also by the dynamics of whisking behavior. As described above, the complement of mystacial vibrissae forms an almost fluid-like mosaic of mechanical sensors extending laterally and rostrally as much as $50 \mathrm{~mm}$ around the animal's head. Whisker movements are rhythmic and rapid, so much so that, viewed in real time, the whisker field appears only as a blur. Viewed in slow motion, it is clear that, within a fraction of a second, rats repeatedly scan a surface with their vibrissae and, in so doing, derive information about its texture. Neurophysiological studies of central, but not peripheral, neurons have demonstrated time-dependent excitatory and/or inhibitory interactions among inputs from different mechanoreceptors within a hair follicle and from different vibrissae on the face (see Lichtenstein et al., 1990). Such spatiotemporal integration may provide a basis for the extraction of spatial detail through the use of a flexible, disjunctive periphery that, in its operation, lacks absolute and static reference coordinates. The extent to which processing of information from parallel inputs (i.e., different vibrissae) contribute to vibrissal discriminations might be assessed by identifying behavioral tasks that minimally require 2 adjacent whiskers. Such tasks probably involve texture or form discrimination, because detection tasks can be performed successfully with only a single whisker (Hutson and Masterton, 1986).

\section{References}

Armstrong-James M, Fox K (1987) Spatiotemporal convergence and divergence in the rat SI "barrel" cortex. J Comp Neurol 263:265281.

Carvell GE, Simons DJ (1988a) Membrane potential changes in rat SmI cortical neurons evoked by controlled stimulation of mystacial vibrissae. Brain Res 448:186-191.

Carvell GE, Simons DJ (1988b) Vibrissal tactile discrimination in the rat. Neurosci Abstr 14:716.

Chapin JK (1986) Laminar differences in sizes, shapes, and response profiles of cutaneous receptive fields in the rat SI cortex. Exp Brain Res 62:549-559.

Darian-Smith I (1984) The sense of touch: performance and peripheral neural processes. In: Handbook of physiology. I. The nervous system. Vol III. Sensory processes (Darian-Smith I ed), pp 739-787. American Physiological Society.

Dörfl J (1982) The musculature of the mystacial vibrissae of the white mouse. J Anat 135:147-154.

Essick GK, Whitsel BL (1985) Factors influencing cutaneous directional sensitivity: a correlative psychophysical and neurophysiological investigation. Brain Res Rev 10:213-230.

Essick GK, Whitsel BL (1988) The capacity of human subjects to process directional information provided at two skin sites. Somatosens Mot Res 6:1-20.

Favorov O, Whitsel BL (1988) Spatial organization of the peripheral input to area 1 cell columns. II. The forelimb representation achieved by a mosaic of segregates. Brain Res Rev 13:43-56.

Favorov O, Diamond M, Whitsel BL (1987) Evidence for a mosaic representation of the body surface in area $3 b$ of the somatic cortex of cat. Proc Natl Acad Sci USA 84:6606-6610.

Ferrington DG, Rowe M (1980) Differential contributions to coding of cutaneous vibratory information by cortical somatosensory areas I and II. J Neurophysiol 43:310-331.

Gardner EP, Costanzo RM (1980a) Spatial integration of multiplepoint stimuli in primary somatosensory cortical receptive fields of alert monkeys. J Neurophysiol 43:420-443.

Gardner EP, Costanzo RM (1980b) Temporal integration of multiplepoint stimuli in primary somatosensory cortical receptive fields of alert monkeys. J Neurophysiol 43:444-468.

Guic-Robles E, Valdivieso C, Guajardo G (1989) Rats can learn a roughness discrimination using only their vibrissal system. Behav Brain Res 31:285-289.

Gustafson JW, Felbain-Keramidas SL (1977) Behavioral and neural approaches to the function of the mystacial vibrissae. Psychol Bull 84:477-488

Hellweg FC, Schultz W, Creutzfeldt OD (1977) Extracellular and intracellular recordings from cat's cortical whisker projection area: thalamocortical response transformation. J Neurophysiol 40:463-479.

Hutson KA, Masterton RB (1986) The sensory contribution of a single vibrissa's cortical barrel. J Neurophysiol 56:1196-1223.

Ibrahim L, Wright EA (1975) The growth of rats and mice vibrissae under normal and some abnormal conditions. J Embryol Exp Morph 33:831-844.

Ito M (1981) Some quantitative aspects of vibrissa-driven neuronal responses in rat neocortex. J Neurophysiol 46:705-715.

Lamb GD (1983) Tactile discrimination of textured surfaces: psychophysical performance measurements in humans. J Physiol (Lond) 338: $551-565$.

Lichtenstein SH, Carvell GE, Simons DJ (1990) Responses of rat trigeminal ganglion neurons to movements of vibrissae in different directions. Somatosens Mot Res 7:47-65.

Morley JW, Goodwin AW, Darian-Smith I (1983) Tactile discrimination of gratings. Exp Brain Res 49:291-299.

Mountcastle VB, Powell TPS (1959) Neural mechanisms subserving cutaneous sensibility, with special reference to the role of afferent inhibition in sensory perception and discrimination. Bull Johns Hopkins Hosp 105:201-232. 
Mountcastle VB, Talbot WH, Sakata H, Hyvärinen J (1969) Cortical ncuronal mechanisms in fluttcr-vibration studied in unanesthetized monkeys: neuronal periodicity and frequency discrimination. $\mathrm{J} \mathrm{Neu-}$ rophysiol 32:452-484

Rice F, Mance A, Munger BL (1986) A comparative light microscopic analysis of the sensory innervation of the mystacial pad. I. Innervation of vibrissal follicle-sinus complexes. J Comp Neurol 252:154-174.

Richardson F (1909) A study of sensory control in the rat. Psychol Rev Mon Sup 12:1-124.

Shipley MT (1974) Response characteristics of single units in the rat's trigeminal nuclei to vibrissa displacements. J Neurophysiol 37:7390.

Simons DJ (1978) Response properties of vibrissa units in the rat SI somatosensory neocortex. J Neurophysiol 41:798-820.

Simons DJ (1985) Temporal and spatial integration in the rat SI vibrissa cortcx. J Ncurophysiol 54:615-635.

Simons DJ, Carvell GE (1989) Thalamocortical response transformation in the rat vibrissa/barrel system. J Neurophysiol 61:311-330.

Vincent SB (1912) The function of vibrissae in the behavior of the white rat. Behavior Mon 1:1-82.

Waite PME (1973) The responses of cells in the rat thalamus to mechanical movements of the whiskers. J Physiol (Lond) 228:541-561.
Welker C (1971) Microelectrode delineation of fine grain somatotopic organization of $\mathrm{SmI}$ cerebral neocortex in albino rat. Brain Res 26 : 259-275.

Welker WI (1964) Analysis of sniffing of the albino rat. Behaviour 12: 223-244.

Wineski LE (1983) Movements of the cranial vibrissae in the golden hamster (Mesocritus auratus). J Zool Lond 200:261-280.

Wineski LE (1985) Facial morphology and vibrissal movement in the golden hamster. J Morphol 183:199-217.

Woolsey TA (1967) Somatosensory, auditory and visual cortical areas of the mouse. Bull Johns Hopkins Hosp 121:91-112.

Woolsey TA, Van der Loos H (1970) The structural organization of layer IV in the somatosensory region (SI) of mouse cerebral cortex. Brain Res 17:205-242.

Woolsey TA, Durham D, Harris R, Simons DJ, Valentino K (1981) Somatosensory development. In: The development of perception: psychobiological perspectives (Aslin RN, Pisani DB, eds), pp 259292. New York: Academic.

Zucker E, Welker WI (1969) Coding of somatic sensory input by vibrissal neurons in the rat's trigeminal ganglion. Brain Res 12:138156. 